\title{
OS IMPACTOS AMBIENTAIS DOS RESÍDUOS SÓLIDOS URBANOS
}

Fâmela Aloma Alves do Nascimento ${ }^{1}$, Jorge Luís de Oliveira Pinto Filho ${ }^{2}$

${ }^{1}$ Bacharela em Engenharia Civil pela Universidade Federal do Semiárido (UFERSA), Discente do Mestrado Acadêmico em Planejamento e Dinâmicas Territoriais no Semiárido, Campus Pau dos Ferros- RN.

E-mail: famela.nascimento@hotmail.com

${ }^{2}$ Professor do Mestrado Acadêmico em Planejamento e Dinâmicas Territoriais no Semiárido, Campus Pau dos Ferros- RN.

E-mail: jorge.filho@ufersa.edu.br

Recebido em: 15/11/2021 - Aprovado em: 15/12/2021 - Publicado em: 30/12/2021

DOI: 10.18677/EnciBio_2021D35

trabalho licenciado sob licença Creative Commons Attribution-NonCommercial-NoDerivatives 4.0 International License.

\section{RESUMO}

Os impactos ambientais resultantes das múltiplas formas de disposição de resíduos sólidos em lixões ou aterros, estabelecem relevantes fontes de exposição humana a inúmeras substâncias tóxicas. Sendo assim, o presente trabalho objetivou-se realizar uma Revisão Sistemática de Literatura sobre os impactos ambientais decorrentes dos resíduos sólidos urbanos entre os anos de 2012 a 2020. As bases de dados escolhidas foram: Scientific Eletronic Library Online - Scielo e portal Capes, com as palavras-chave: Resíduos sólidos urbanos; Impactos ambientais; Contaminação; Disposição final. Foram identificados 3.201 trabalhos, porém, pela avaliação da qualidade das evidências foram selecionados 273 artigos para a leitura, dentre estes, foram escolhidos 14 trabalhos que mais atendiam os critérios estabelecidos no objetivo da pesquisa para compor o estudo. Entre os anos estudados, destacaram-se em número de publicações os anos de 2018 e 2019, os estados de Minas Gerais e Rio Grande do Sul apresentaram os maiores índices de publicação. Em relação as áreas do ensino, destacou-se pelo número de publicações, a área de engenharias e meio ambiente. Acerca dos impactos ambientais oriundos da destinação inadequada dos resíduos sólidos urbanos, 90,9\% das pesquisas apresentam danos ambientais decorrentes da destinação e disposição dos resíduos sólidos urbanos; seguido da contaminação do solo com $72,7 \%$ de citações; logo após os danos à saúde humana com $63,6 \%$ e, finalmente com a contaminação da água com $54,5 \%$. Portanto, deve-se propor mais pesquisas sobre a temática, visto que a informação, junto com educação ambiental podem promover uma sensibilização e cobrança da aplicação da Política Nacional de Resíduos sólidos.

PALAVRAS-CHAVE: Contaminação; Impactos ambientais; resíduos sólidos urbanos

\section{THE ENVIRONMENTAL IMPACTS OF URBAN SOLID WASTE}

\begin{abstract}
The environmental impacts resulting from the multiple forms of solid waste disposal in dumps or landfills establish relevant sources of human exposure to numerous toxic substances. Therefore, the present work aimed to carry out a Systematic Literature Review on the environmental impacts of urban solid waste between the years 2012 to
\end{abstract}


2020. The chosen databases were: Scientific Electronic Library Online - Scielo and Capes portal, with the keywords Urban solid waste; Environmental impacts; Contamination; Final disposition. 3,201 works were identified, however, by evaluating the quality of evidence, 273 articles were selected for reading, among these, 14 works were chosen that best met the criteria established in the research objective to compose the study. Among the years studied, the years 2018 and 2019 stood out in number of publications, the states of Minas Gerais and Rio Grande do Sul had the highest publication rates. Regarding the areas of education, the area of engineering and the environment stood out due to the number of publications. Regarding the environmental impacts arising from the inadequate disposal of urban solid waste, $90.9 \%$ of the surveys show environmental damage arising from the destination and disposal of urban solid waste; followed by soil contamination with $72.7 \%$ of citations; right after damage to human health with $63.6 \%$ and finally with water contamination with $54.5 \%$. Therefore, more research on the subject should be proposed, since information, together with environmental education, can promote awareness and demand for the application of the National Solid Waste Policy.

KEYWORDS: Environmental impacts, solid urban waste, contamination.

\section{INTRODUÇÃO}

O consumismo é o eixo central entre a sociedade, o meio ambiente e a indústria, visto que é um processo que gera a demanda para as indústrias e causa um panorama de instabilidade ambiental com a busca por recursos naturais, que, segundo Braga (2012), são gerenciados de forma inadequada, ocasionando impactos ambientais. Nesta perspectiva, Fogliatti et al., (2014), conceituam um impacto ambiental como mudança das características físicas, químicas e/ou biológicas do meio, ocasionadas de forma direta ou indireta pelas ações do ser humano que seja capaz de consternar qualidade de vida ou saúde dos recursos naturais.

Lixões são descritos como lugares destinados a descarga de resíduos sólidos sobre o solo sem medidas de proteção ambiental, o que gera impactos negativos ao meio ambiente, sobretudo no solo e na água. No Brasil, a realidade é exposta através de um cenário desafiador e heterogêneo, já que 72,7 milhões de toneladas de resíduos sólidos coletadas no Brasil em 2018, 59,5\% foram destinados em locais adequados, isto é, aterros sanitários, demonstrando uma expansão de 2,4\% em relação ao valor total do ano anterior, todavia, realizando-se um comparativo com as disposições entre as regiões, pode-se destacar a região Sul do país com a menor quantidade de municípios que destinam os resíduos no lixão (42), em contrapartida, a região Nordeste aponta o maior número de municípios com destinação ao lixão (844) (ABRELPE, 2018).

Diante desta situação, as primeiras iniciativas para a definição de diretrizes legais ligadas à questão dos resíduos sólidos ocorreram no final da década de 1980, no entanto, em 1990 houve efetivação de ações que apontavam para a construção da Política Nacional de Resíduos Sólidos - PNRS. A partir daí, foram desenvolvidos

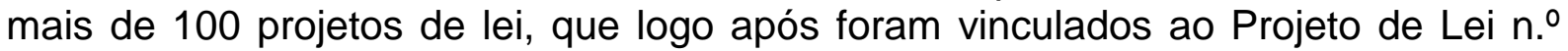
203/91, que apresenta acondicionamento, coleta, tratamento, transporte e destinação dos resíduos de serviços de saúde (BRASIL, 2010).

Especificamente nos municípios brasileiros as referidas políticas, apresentamse como um desafio diante das dificuldades financeiras, institucionais e de funcionários qualificados para atuar nesta área, principalmente tratando-se dos menores. Diante deste quadro de fragilidades na efetivação da gestão de resíduos sólidos em cidades brasileiras, torna-se crucial compreender a extensão desta 
problemática, visto que a destinação inadequada propicia a proliferação de vetores e de agentes transmissores de doenças, a poluição do solo, a emissão de partículas e poluentes atmosféricos, entre outros inúmeros impactos (MAIELLO, 2018).

Neste sentido, alguns autores como Vasconcelos (2018), Reis et al. (2016), Fratta et al. (2019), Leite et al. (2021), dentre outros, trazem a temática de resíduos sólidos em artigos de revisão sistemáticas, porém, os mesmos não retratam os impactos ambientais resultantes da destinação inadequada dos resíduos sólidos, sendo necessário investigar trabalhos que caracterizem os impactos ambientais e sociais oriundos da destinação inadequada dos resíduos sólidos urbanos para que conhecendo-os seja possível a busca de mecanismos para dirimir, prevenir e/ou controlar tais impactos socioambientais, permitindo assim a possibilidade de diminuição dos conflitos sociais, econômicos, ambientais, políticos, territoriais e, saúde pública.

A pesquisa teve por objetivo geral realizar uma Revisão Sistemática de Literatura - RSL sobre a temática de resíduos sólidos urbanos entre os anos de 2012 a 2020. Para isso, definiram-se como objetivos específicos: caracterizar a produção científica sobre resíduos sólidos urbanos; identificar os principais impactos ambientais citados pelos autores e mencionar as consequências dos destinos inadequados dos resíduos sólidos urbanos relatados pelos investigadores.

\section{MATERIAL E MÉTODOS}

A direção da pesquisa pautou-se na determinação da classificação da pesquisa, demarcação do objeto de estudo e demarcação dos procedimentos metodológicos apropriados.

\section{Classificação da Pesquisa}

O estudo possui uma abordagem dedutiva partindo da observação e leitura dos materiais apresentados no mesmo, sendo organizado em cinco etapas, a saber: objetivos, procedimentos técnicos, método de abordagem, métodos de procedimento e tipologia (MARCONI; LAKATOS, 2017).

Desse modo, a pesquisa é classificada quanto aos seus objetivos, em: exploratória, que tem por atribuição potencializar, elucidar e mudar conceitos e ideologias para levantar problemas mais precisos e montar hipóteses, visto que possibilita uma visão completa do fato; descritivo, que tem por objetivo detalhar as características de certa população ou fenômeno e/ou a determinação de relação entre variáveis; e explicativo, que tem por finalidade reconhecer as razões que determinam ou colaboram para o acontecimento dos fenômenos (GIL, 2017).

$\mathrm{Na}$ perspectiva de estudar e avaliar os impactos ambientais resultantes da disposição inadequada dos resíduos sólidos, este estudo foi desenvolvido com metodologias técnicas que proporcionam a classificação em: pesquisa bibliográfica que consiste no levantamento da bibliografia já publicada sobre o assunto em periódicos, livros, teses entre outros. Pesquisa documental, que se refere à coleta de informações secundárias e sem tratamento analítico; estudo de caso, que tem por finalidade realizar pesquisas acentuadas, com um ou limitados objetos, conseguindo conhecimento vasto e aprofundado e dados de campo, por meio dos quais se obtêm dados primários (GIL, 2017). Desta forma, foi realizada uma pesquisa bibliográfica visando o fornecimento de uma série de acontecimentos mais amplos em relação ao que os pesquisadores poderiam conseguir diretamente.

Ao demarcar os procedimentos técnicos do estudo, estabeleceu-se a forma de direção, que será realizada pelo procedimento de abordagem indutivo, 
fundamentado na experiência e na observação que resulta em algo novo e fenomenológico, que compreende a descrição direta da experiência tal como ela é, sem haver consideração sobre a gênese e dos esclarecimentos causais que os especialistas podem dar (GIL, 2017). Com isto, os pesquisadores observarão os diferentes resultados gerados com a disposição dos resíduos sólidos urbanos, analisando as consequências ambientais de forma geral.

Na perspectiva desta pesquisa, adotam-se métodos técnicos que possibilitam a objetividade no estudo, sendo, neste caso, empregado o método monográfico, que propõe investigar qualquer caso que se analise de forma profunda e que pode representar muitos outros ou até todos os casos similares. Para tanto, o trabalho adota a forma quali-quantitativa para exposição dos resultados. Sendo que pretendeu-se descrever, explicar, como também utilizar técnicas estatísticas para apresentação dos dados (MARCONI; LAKATOS, 2017).

\section{Caracterização do Objeto de Estudo}

Cezar et al. (2015) afirma que dentre as iniciativas desenvolvidas no Brasil, é evidenciada a política nacional dos resíduos sólidos (PNRS), designada pela Lei no 12.305, que desde 2010 instituiu as diretrizes direcionadas especialmente para o setor. Com a fundação da referida Lei é consolidado um marco legal que até então não existia no âmbito dos resíduos sólidos o que também modificou no aspecto acadêmico, visto que as pesquisas ganharam mais notoriedade, uma vez que que a PNRS tornou-se base para construção de artigos científicos na área.

Após a descrição da conjuntura nacional e global das publicações nos últimos 20 anos no âmbito de resíduos sólidos, Deus (2015) apresenta resultados que revelam aumento no número de publicação científica nacional. $\mathrm{O}$ autor afirma que a instituição da PNRS não pode ser considerado uma razão fundamental para tal crescimento, sabendo que já existia uma tendência de aumento, porém não se pode dispensar sua importância.

\section{Procedimentos metodológicos}

Os procedimentos metodológicos deste estudo se deram através dos seguintes passos: i) definição da temática de estudo; ii) definição dos instrumentos de estudo; iii) obtenção, organização e tratamento dos dados.

Etapa I - Definição da temática do estudo

A delimitação da presente abordagem se deu com a definição da caracterização da produção científica sobre os resíduos sólidos urbanos entre os anos de 2012 a 2020 com a finalidade de realizar a identificação dos principais impactos ambientais observados pelos pesquisadores.

Etapa II - Definição dos instrumentos de estudo

Para viabilizar o estudo, adotaram-se técnicas de coletas de dados, que são fundamentados em Marconi e Lakatos (2017) como um conjunto de preceitos ou processos de que se serve uma ciência e as atribuições para usar esses preceitos ou normativos na aquisição de seus propósitos.

Etapa III - obtenção, organização e tratamento dos dados

Os passos para a realização da revisão sistemática sobre os impactos ambientais dos resíduos sólidos urbanos foram:

i) Seleção da base das bases de dados em que as publicações foram pesquisadas (Scientific Eletronic Library Online - Scielo e portal Capes); 
ii) Seleção dos termos pesquisados conforme objeto de estudo e melhor combinação entre os mesmos: Resíduos sólidos urbanos; Impactos ambientais; Contaminação; Disposição final.

iii) Extração dos trabalhos para leitura;

iv) Escolha dos parâmetros de exclusão, para refinar as publicações encontradas na busca;

v) Análise dos resultados encontrados;

vi) Conclusões acerca dos resultados.

As palavras escolhidas para busca dos artigos foram selecionadas a partir da análise das palavras-chave com maior vínculo com o tema em estudo. O Quadro 01 apresenta a identificação do número de publicações geradas por cada palavra e combinação de palavras nas bases de dados selecionadas sem utilização de filtros

QUADRO 1. Resultados da pesquisa nas bases de dados selecionadas - Sem utilização de filtros

\begin{tabular}{c|c|}
\multirow{2}{*}{ Palavras } & Publicações \\
\cline { 2 - 2 } & $\begin{array}{c}\text { Scientific Eletronic Library } \\
\text { Online -Scielo }\end{array}$ \\
\hline Impactos ambientais dos resíduos sólidos urbanos & 14 \\
\hline Resíduos sólidos urbanos and contaminação & 21 \\
\hline Resíduos sólidos urbanos and disposição final & 26 \\
\hline Poluição and resíduos sólidos urbanos & 11 \\
\hline Total & 72
\end{tabular}

Através da análise do Quadro 1 percebe-se a identificação de 72 artigos na base de dados Scielo e 3.129 artigos no Portal Capes, totalizando 3.201 artigos na busca sem filtros. Posteriormente foram selecionados filtros para refinar os resultados: A pesquisa considerou apenas artigos com delimitação temporal entre 2012 e 2020 conforme apresenta o Quadro 02.

QUADRO 2. Resultados da pesquisa nas bases de dados selecionadas - Com utilização de filtros

\begin{tabular}{c|c|}
\multirow{2}{*}{ Palavras } & \begin{tabular}{c} 
Publicações \\
\cline { 2 - 2 }
\end{tabular} \\
$\begin{array}{cc}\text { Scientific Eletronic Library } \\
\text { Online - Scielo }\end{array}$ \\
\hline Impactos ambientais dos resíduos sólidos urbanos & 6 \\
\hline Resíduos sólidos urbanos and contaminação & 12 \\
\hline Resíduos sólidos urbanos and disposição final & 16 \\
\hline Poluição and resíduos sólidos urbanos & 5 \\
\hline Total & 39
\end{tabular}

Através dos filtros foram encontrados 39 artigos na base scielo e 2.345 no Portal Capes, totalizando 2.384 artigos identificados. Foram excluídos os artigos repetidos e que não estavam dentro da temática do estudo. Assim, pela avaliação da qualidade das evidências foram selecionados 273 artigos para a leitura, dentre estes, foram escolhidos 14 trabalhos que mais atendiam os critérios estabelecidos no objetivo da pesquisa para compor o estudo.

Os dados foram apresentados seguindo a ordem de discussão: Caracterização da produção científica sobre resíduos sólidos urbanos, identificação dos principais impactos ambientais do manejo de resíduos sólidos urbanos e 
determinação das consequências dos destinos inadequados dos resíduos sólidos urbanos.

\section{RESULTADOS E DISCUSSÃO}

\section{Caracterização da produção científica sobre resíduos sólidos urbanos}

A caracterização da produção científica sobre resíduos sólidos urbanos aborda os anos de realização dos estudos, estados, áreas e métodos científicos utilizados. A Figura 1 apresenta um resumo dos anos em que as pesquisas analisadas foram realizadas, percebendo-se que os anos de 2018 e 2019 apresentam os maiores números de publicações $(21,42 \%$ e $28,57 \%)$, respectivamente, seguido dos anos de 2012 e 2020, que apresentam 14,28\%, do total das publicações. Os anos de 2015, 2016 e 2017 apresentaram um total de $7,14 \%)$ percebendo-se um aumento das publicações com o passar dos anos, tal fenômeno pode ser explicado pela efetivação da Política Nacional de Resíduos Sólidos que trouxe ao Brasil novas possibilidades em relação aos resíduos sólidos, gerando metas com a finalidade de extinguir lixões e aterros irregulares (BRASIL, 2010), além de tornar-se um assunto relevante no meio acadêmico, com a finalidade de despertar a sociedade para os impactos ambientais decorrentes destes.

FIGURA1. Anos de realização dos estudos

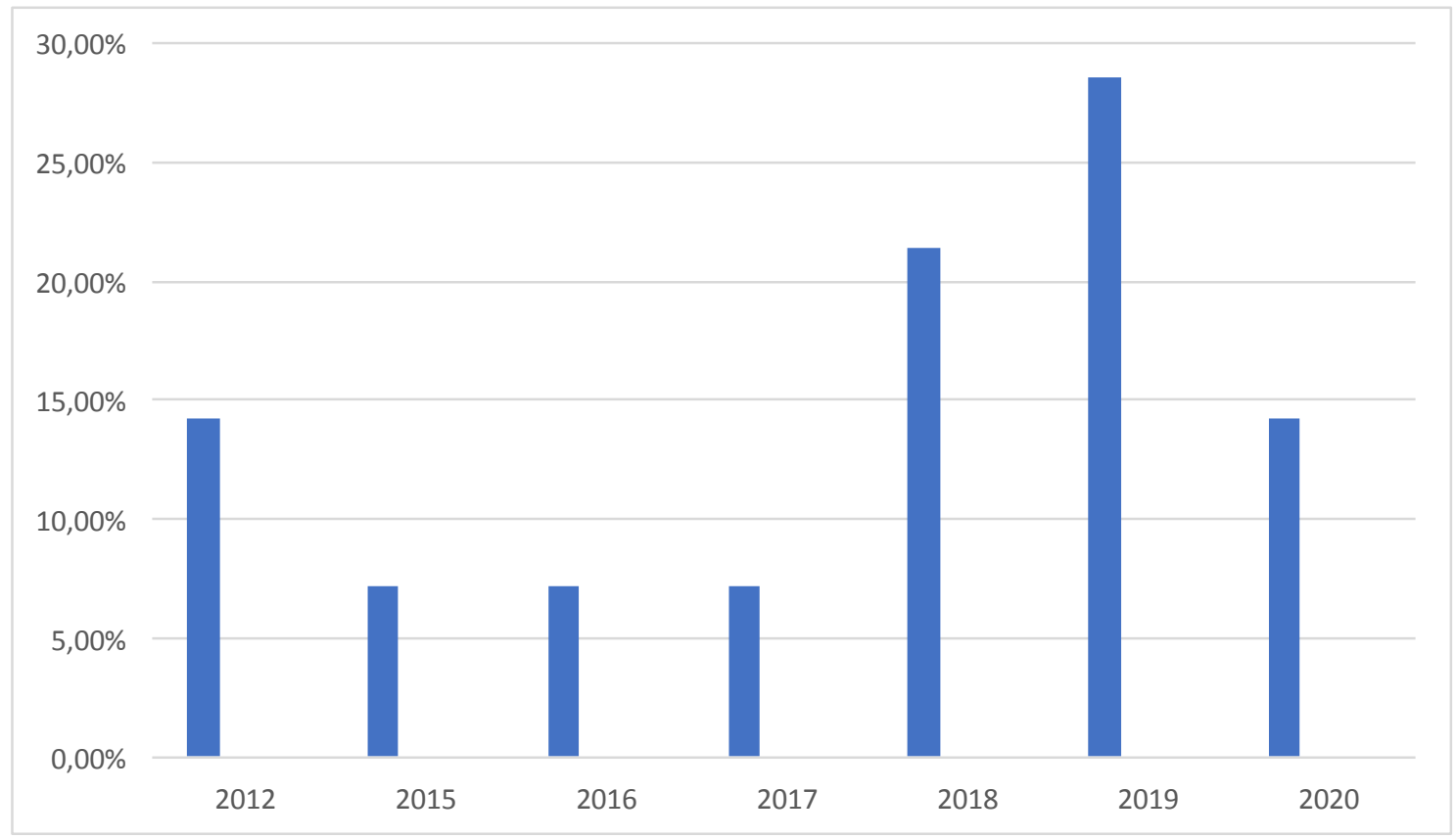

Fonte: Autores (2021).

Deve-se ressaltar também que com o passar dos anos a geração de resíduos aumentou, fato explicado pelo crescimento da população e das cidades, incluindo o progresso das indústrias e a produção de bens de consumo. Ferreira (2020) corrobora quando afirma que com o passar dos anos, quanto mais cresce a população, mais lixo se fabrica, assim, o problema acentua-se e a academia deve enaltecer o assunto, além de trazer a problemática do consumo, considerando-o como um forte determinante dos impactos ambientais globais.

De acordo com a ABRELPE (2018) entre os anos de 2017 e 2018, a geração de resíduos sólidos no Brasil aumentou quase 1\%, totalizando 216.629 toneladas diárias. Fazendo um comparativo com a população que também cresceu no período 
$(0,40 \%)$, a geração per capita teve elevação um pouco menor $(0,39 \%)$. Em média, cada brasileiro produziu em torno de 1 quilo de resíduo por dia. Este aumento foi considerável em todas as regiões, exceto o Nordeste, que segundo o Instituto Brasileiro de Geografia e Estatística teve decréscimo populacional. Destaca-se a região Sudeste com o maior percentual de resíduos coletados. A região citada chega a índices de 53,2 \% no ano de 2018 em relação ao território brasileiro, o que justifica a necessidade da realização de pesquisas sobre a temática no Brasil.

A Figura 2 mostra os estados brasileiros em que as pesquisas foram realizadas, enaltecendo a região sudeste, representada pelo estado de Minas Gerais $(28,57 \%)$ com o maior número de publicações, resultado da preocupação com o aumento da coleta de resíduos sólidos na região que passou de 103.741 toneladas/dia em 2017 para 105.977 toneladas/dia em 2018. O estudo indicou grande número de pesquisas oriundas do Rio Grande do Sul $(21,42 \%)$, visto que a região Sul passou de 21.327 toneladas.dia $^{-1}$ coletados em 2017 para 21.561 toneladas/ dia coletados em 2018 (ABRELPE,2018).

FIGURA 2. Estados de realização dos estudos

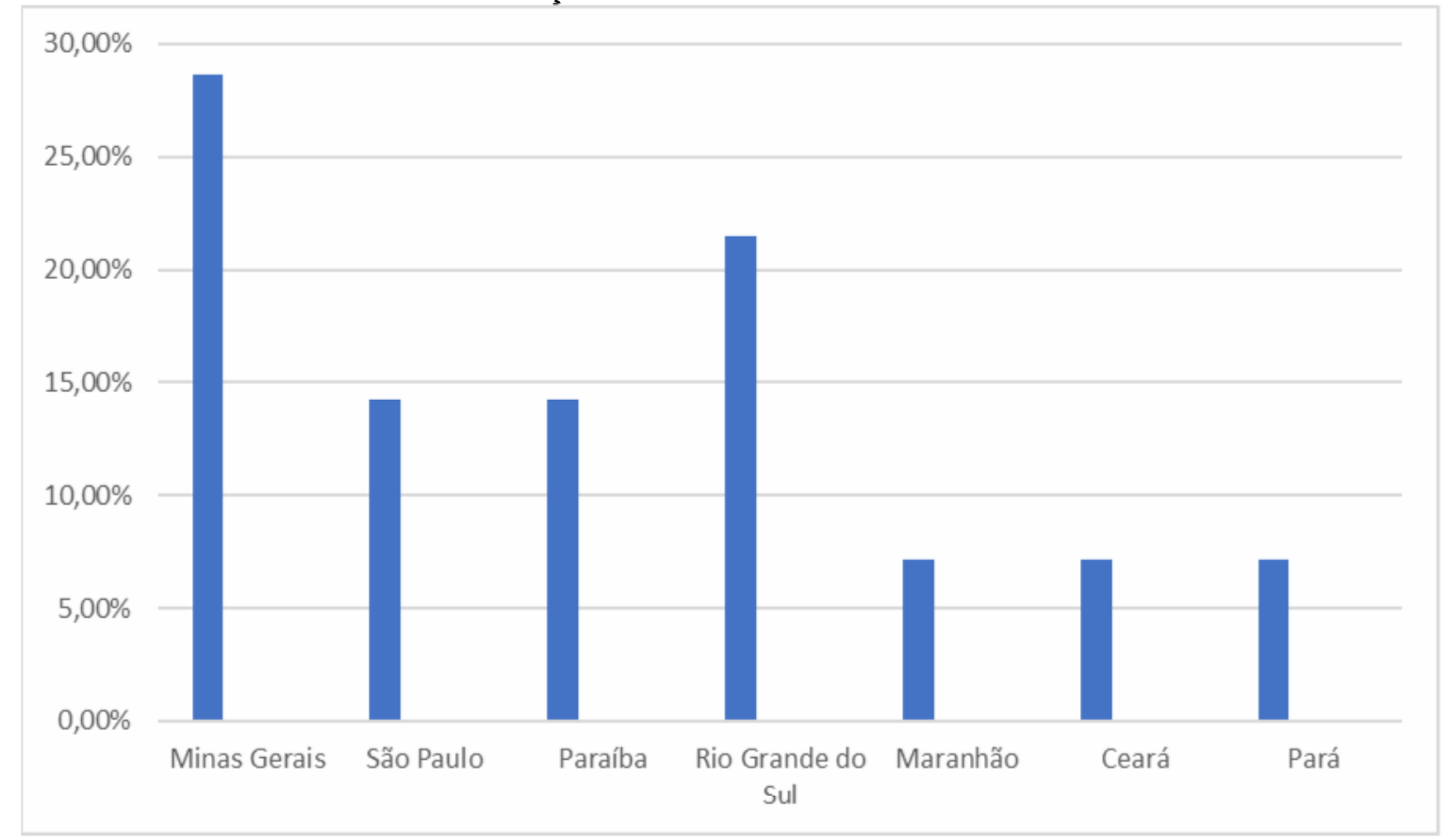

Fonte: Autores (2021).

A Figura 3 apresenta as áreas em que foram realizadas as pesquisas analisadas neste estudo, sendo que nos artigos lidos notou-se a presença das engenharias e meio ambiente, ciências agrárias, ciências humanas e ciências da saúde, de forma que engenharias e meio ambiente apresentou-se como a área que mais publicou sobre as temáticas pesquisadas com $(68,75 \%)$ do total de publicações, consequência também da Resolução Confea no 1002/2002 que instaura o Código de Ética para o desempenho da engenharia e arquitetura no Brasil. No âmbito das doutrinas éticas desse código o Princípio VI se sobressai, orientando que a intervenção profissional sobre os ambientes naturais e construídos deve propiciar o desenvolvimento sustentável, em concordância com a Agenda 21.

Assim, deve-se buscar mudanças de paradigmas no que diz respeito a relação da produção e o meio ambiente, apresentando o uso eficiente de materiais e energias renováveis, não danosos, ao mesmo tempo, conservando a 
biodiversidade. Em seguida destaca-se as ciências agrárias com (18,75\%), as ciências humanas e ciências da saúde com $(6,25 \%)$, do total de publicações.

FIGURA 03. Áreas de realização dos estudos

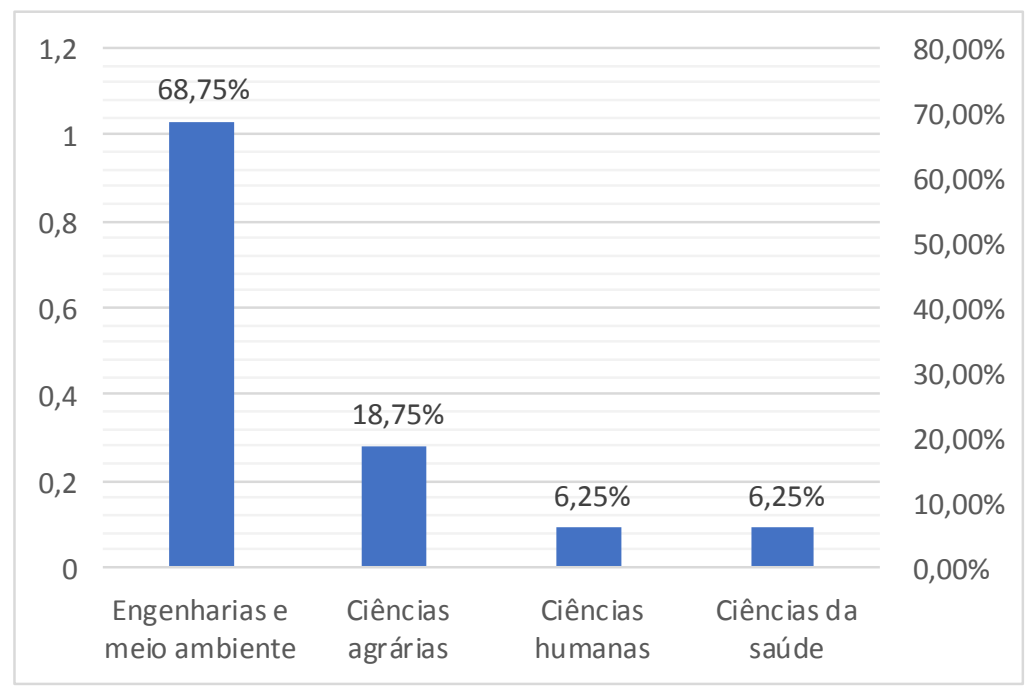

Fonte: Autores (2021).

O Quadro 3 apresenta dados relativos aos métodos utilizados nos trabalhos analisados, isto é, qual a natureza da pesquisa, classificação do estudo, procedimentos metodológicos e o método da coleta dos dados. Assim, quanto à natureza do problema, 42,86\% dos trabalhos analisados apresentaram natureza quantitativa, 42,86\% qualitativa e 14,29\% qualitativa-quantitativa. De acordo com Yin (2005) a abordagem quantitativa tem por finalidade a validação das hipóteses através da utilização de informações estruturadas, estatísticas, abrangendo cálculos como média, moda, mediana, desvio padrão, entre outras técnicas. Já a pesquisa qualitativa averigua sob um ambiente natural e interpreta as ocorrências de acordo com os conceitos atribuídos pelos participantes, isto é, a análise do discurso ou análise de conteúdo. Deve-se ressaltar que abordagem não elimina, de forma que podem se complementar para melhorar o entendimento do estudo, dessa maneira percebe-se a necessidade da junção das abordagens para uma apresentação de dados mais completa na área investigada.

Em relação aos objetivos da pesquisa, 35,71\% são descritivos, isto é, não tem comprometimento em explicar os acontecimentos que descreve, ainda que sirva de base para tal explicação. Em contrapartida, 64,29\% são descritivos exploratórios, sendo a junção do objetivo descritivo que detalha as características de certas populações ou fenômenos e exploratórios por possibilitarem superior domínio com o problema, ou seja, esclarecer (GIL, 2017). percebeu-se que os autores além de descrever o problema, tentavam maior esclarecimento acerca do assunto.

Quanto aos procedimentos metodológicos $71,43 \%$ dos estudos realizaram estudos a partir de caso analisados, que de acordo com Yin (2005), vem sendo usado com maior frequência pelos pesquisadores sociais, com diversas finalidades, dentre estas a exploração de situações da vida real, descrição da situação do contexto em que está sendo realizada certa investigação e explicação de variáveis de causa de determinado acontecimento em situações muito complicadas que não viabilizam a utilização de levantamentos e experimentações, $28,57 \%$ de pesquisa documental, que segundo Gil (2019), procedimento que utiliza materiais que não receberam ainda uma abordagem analítica, ou que ainda podem ser recriados 
segundo os objetos da pesquisa. Além de investigar os documentos chamados de "primeira mão" que são documentos de arquivos, igrejas, sindicatos, instituições, entre outros, ainda existem aqueles que já foram processados, porém, podem ganhar outras interpretações, como por exemplo relatórios de empresas, tabelas, entre outros.

Os métodos de coleta de dados foram: Análise documental 35,71\%; Coleta de solo e água para análise de contaminação $28,57 \%$; Visitas de campo e entrevistas 14,29\%; Análise documental e visitas de campo 14,29\%; Análise documental e entrevistas $7,14 \%$.

QUADRO 3. Métodos científicos utilizados nos estudos

\begin{tabular}{|c|c|c|c|c|}
\hline Autor & $\begin{array}{l}\text { Natureza da } \\
\text { pesquisa }\end{array}$ & Classificação do estudo & $\begin{array}{l}\text { Procedimentos } \\
\text { metodológicos }\end{array}$ & $\begin{array}{c}\text { Método de coleta de } \\
\text { dados }\end{array}$ \\
\hline PINHEIRO et al. & Quantitativo & Descritivo exploratório & Estudo de caso & $\begin{array}{c}\text { Coleta de solo e água } \\
\text { para análise de } \\
\text { contaminação }\end{array}$ \\
\hline GOLVEIA & Qualitativo & Descritivo & Pesquisa documental & Análise documental \\
\hline $\begin{array}{c}\text { MARQUES et } \\
\text { al. }\end{array}$ & Quantitativo & Descritivo exploratório & Estudo de caso & $\begin{array}{c}\text { Coleta de solo e água } \\
\text { para análise de } \\
\text { contaminação }\end{array}$ \\
\hline AZEVEDO et al. & Qualitativo & Descritivo exploratório & Estudo de caso & $\begin{array}{c}\text { Visitas de campo e } \\
\text { entrevistas }\end{array}$ \\
\hline ANDRADE et al. & Quantitativo & Descritivo exploratório & Pesquisa documental & $\begin{array}{l}\text { Análise documental e } \\
\text { visitas de campo }\end{array}$ \\
\hline $\begin{array}{c}\text { FRACASSO et } \\
\text { al. }\end{array}$ & Qualitativo & Descritivo & Pesquisa documental & Análise documental \\
\hline $\begin{array}{l}\text { CARBONAI et } \\
\text { al. }\end{array}$ & Qualitativo & Descritivo & Estudo de caso & Análise documental \\
\hline SOUZA et al. & Qualitativo & Descritivo exploratório & Estudo de caso & $\begin{array}{l}\text { Análise documental e } \\
\text { entrevistas }\end{array}$ \\
\hline FREIRE et al. & $\begin{array}{l}\text { Qualitativo e } \\
\text { quantitativo }\end{array}$ & Descritivo exploratório & Estudo de caso & $\begin{array}{c}\text { Visitas de campo e } \\
\text { entrevistas }\end{array}$ \\
\hline MELO et al. & Quantitativo & Descritivo exploratório & Estudo de caso & $\begin{array}{c}\text { Coleta de solo e água } \\
\text { para análise de } \\
\text { contaminação }\end{array}$ \\
\hline $\begin{array}{c}\text { RODRIGUES et } \\
\text { al. }\end{array}$ & Qualitativo & Descritivo & Estudo de caso & Análise documental \\
\hline MILHOME et al. & $\begin{array}{l}\text { Qualitativo e } \\
\text { quantitativo }\end{array}$ & Descritivo exploratório & Estudo de caso & $\begin{array}{l}\text { Coleta de solo para } \\
\text { análise de } \\
\text { contaminação }\end{array}$ \\
\hline NOVAIS et al. & Quantitativo & Descritivo & Pesquisa documental & Análise documental \\
\hline OLIVEIRA et al. & Quantitativo & Descritivo exploratório & Estudo de caso & $\begin{array}{c}\text { Coleta de solo para } \\
\text { análise de } \\
\text { contaminação }\end{array}$ \\
\hline Total & $\begin{array}{c}\text { Quantitativo } \\
\text { 42,86\%; } \\
\text { Qualitativo } \\
\text { 42,86\%; } \\
\text { Quantitativo } \\
\text { e Qualitativo } \\
14,29 \%\end{array}$ & $\begin{array}{c}\text { Descritivo exploratório } \\
35,71 \% \\
\text { Descritivo } 35,71 \%\end{array}$ & $\begin{array}{c}\text { Estudo de caso } \\
71,43 \% \\
\text { Pesquisa documental } \\
28,57 \%\end{array}$ & $\begin{array}{c}\text { Análise documental } \\
35,71 \% ; \\
\text { Coleta de solo e água } \\
\text { para análise de } \\
\text { contaminação } 28,57 \% ; \\
\text { Visitas de campo e } \\
\text { entrevistas } 14,29 \% ; \\
\text { Análise documental e } \\
\text { visitas de campo } \\
14,29 \% ; \\
\text { Análise documental e } \\
\text { entrevistas } 7,14 \% \\
\end{array}$ \\
\hline
\end{tabular}




\section{Identificação dos principais impactos ambientais do manejo de resíduos sólidos urbanos}

A identificação dos principais impactos ambientais do manejo de resíduos sólidos urbanos esta demonstrada no Quadro 4 que apresenta a relação dos objetivos, respectivas palavras-chave e principais resultados encontrados no intervalo de tempo do estudo proposto, sendo possível observar que os objetivos mais citados estão a identificação, avaliação e diagnóstico da contaminação do meio ambiente decorrente da disposição inadequada dos resíduos sólidos urbanos, sobretudo ocasionada por vazadouros a céu aberto, isto é, lixões.

QUADRO 4. Objetivos do estudo, palavras-chave e principais resultados

\begin{tabular}{|c|c|c|c|}
\hline Tema & Objetivos do estudo & Palavras-Chave & Principais resultados \\
\hline $\begin{array}{l}\text { Diagnóstico de áreas } \\
\text { contaminadas pela } \\
\text { disposição final de } \\
\text { resíduos sólidos no } \\
\text { município de Paço do } \\
\text { Lumiar (MA) }\end{array}$ & $\begin{array}{c}\text { Detectar áreas } \\
\text { contaminadas pela } \\
\text { disposição de resíduos } \\
\text { sólidos em Paço do } \\
\text { Lumiar. }\end{array}$ & $\begin{array}{l}\text { Resíduos sólidos; } \\
\text { disposição final; } \\
\text { contaminação; lixão }\end{array}$ & $\begin{array}{c}\text { O lixão contribui para a } \\
\text { contaminação do solo com } \\
\text { metais pesados no local de } \\
\text { disposição, contaminação } \\
\text { potencial da água subterrânea } \\
\text { em virtude de a geologia local e } \\
\text { o solo arenoso serem } \\
\text { facilitadores no processo de } \\
\text { transporte de contaminantes. } \\
\text { Portanto, como a contaminação } \\
\text { verificada compromete alguns } \\
\text { usos da terra (residencial e } \\
\text { agrícola). }\end{array}$ \\
\hline $\begin{array}{l}\text { Resíduos sólidos urbanos: } \\
\text { impactos socioambientais } \\
\text { e perspectiva de manejo } \\
\text { sustentável com inclusão } \\
\text { social }\end{array}$ & $\begin{array}{l}\text { Apontar caminhos para o } \\
\text { enfrentamento da } \\
\text { questão dos resíduos } \\
\text { sólidos, }\end{array}$ & $\begin{array}{l}\text { Resíduos sólidos, } \\
\text { impactos à saúde, } \\
\text { impactos } \\
\text { ambientais, } \\
\text { reciclagem, } \\
\text { catadores, inclusão } \\
\text { social. }\end{array}$ & $\begin{array}{l}\text { Destaca-se o papel dos } \\
\text { catadores, que vêm realizando } \\
\text { um trabalho de grande } \\
\text { importância ambiental. Dadas } \\
\text { as fragilidades desse segmento } \\
\text { populacional, é preciso delinear } \\
\text { políticas públicas que tornem a } \\
\text { atividade de catação mais digna } \\
\text { e com menos riscos para assim } \\
\text { caminhar rumo a um } \\
\text { desenvolvimento mais } \\
\text { saudável, justo e sustentável. }\end{array}$ \\
\hline $\begin{array}{l}\text { Impactos da disposição } \\
\text { de resíduos sólidos } \\
\text { urbanos na qualidade da } \\
\text { água de superfície em } \\
\text { três cidades de Minas } \\
\text { Gerais - Brasil }\end{array}$ & $\begin{array}{l}\text { Identificar o impacto } \\
\text { ambiental de três } \\
\text { diferentes instalações de } \\
\text { resíduos sólidos urbanos. }\end{array}$ & $\begin{array}{l}\text { Contaminação } \\
\text { ambiental, índice } \\
\text { de qualidade da } \\
\text { água, aterro } \\
\text { sanitário, aterro } \\
\text { controlado, lixão. }\end{array}$ & $\begin{array}{l}\text { As condições da água eram } \\
\text { insatisfatórias devido a } \\
\text { violações das concentrações de } \\
\text { fósforo, amônia, coliformes } \\
\text { fecais e a relação demanda } \\
\text { bioquímica de oxigênio / } \\
\text { demanda química de oxigênio. }\end{array}$ \\
\hline $\begin{array}{c}\text { Diagnóstico da } \\
\text { degradação ambiental na } \\
\text { área do lixão de Pombal - } \\
\text { PB }\end{array}$ & $\begin{array}{c}\text { Diagnóstico qualitativo da } \\
\text { degradação ambiental na } \\
\text { área do lixão de Pombal- } \\
\text { PB. }\end{array}$ & $\begin{array}{l}\text { Resíduos sólidos, } \\
\text { Impactos } \\
\text { ambientais, } \\
\text { Medidas } \\
\text { mitigadoras. }\end{array}$ & $\begin{array}{l}\text { Contaminação do solo, dos } \\
\text { recursos hídricos, do ar } \\
\text { atmosférico; o aumento dos } \\
\text { processos erosivos; redução ou } \\
\text { perda total da fauna e flora; } \\
\text { riscos aos catadores e impacto } \\
\text { na saúde pública. Os fatores } \\
\text { mais afetados foram o } \\
\text { antrópico, o solo, a fauna, a } \\
\text { flora e a paisagem. }\end{array}$ \\
\hline $\begin{array}{c}\text { Análise do gerenciamento } \\
\text { de resíduos sólidos } \\
\text { urbanos na cidade de } \\
\text { Itabira (MG) }\end{array}$ & $\begin{array}{c}\text { Análise da geração e a } \\
\text { destinação dos resíduos } \\
\text { sólidos urbanos na } \\
\text { cidade de Itabira (MG) } \\
\text { nos anos de } 2016 \text { e } 2017 \text {. }\end{array}$ & $\begin{array}{l}\text { Aterro Sanitário; } \\
\text { Coleta seletiva; } \\
\text { Destinação final; } \\
\text { Impactos } \\
\text { ambientais; } \\
\text { Reciclagem. }\end{array}$ & $\begin{array}{l}\text { Crescimento de } 1,9 \% \\
\text { na coleta de resíduos sólidos } \\
\text { urbanos entre os anos de } 2016 \\
\text { e } 2017 \text { e de } 6,6 \% \text { na reciclagem } \\
\text { de resíduos sólidos neste } \\
\text { mesmo período. Aumento de } \\
\text { aproximadamente } 1 \% \text { dos } \\
\text { resíduos encaminhados para o } \\
\text { aterro sanitário. }\end{array}$ \\
\hline
\end{tabular}




\begin{tabular}{|c|c|c|c|}
\hline $\begin{array}{c}\text { Diagnóstico E Prognóstico } \\
\text { Dos RSU Para o } \\
\text { Município De } \\
\text { Sananduva/RS }\end{array}$ & $\begin{array}{l}\text { Diagnóstico e o } \\
\text { prognóstico para a gestão } \\
\text { de resíduos sólidos } \\
\text { urbanos (RSU) do } \\
\text { município de } \\
\text { Sananduva/RS. }\end{array}$ & $\begin{array}{l}\text { Resíduos Sólidos } \\
\text { Urbanos; Gestão; } \\
\text { Meio Ambiente. }\end{array}$ & $\begin{array}{l}\text { A população urbana do } \\
\text { município no período de } \\
\text { set/2012 a ago/2013 teve uma } \\
\text { geração de } 3.577 .440 \mathrm{~kg} \text { de } \\
\text { RSU, com isto, verifica-sea } \\
\text { necessidade da inserção de } \\
\text { novas técnicas de tratamento } \\
\text { final dos RSU, como a } \\
\text { compostagem, coleta } \\
\text { seletiva/logística reversa e } \\
\text { incineração, aliadas a efetiva } \\
\text { conscientização ambiental da } \\
\text { população. }\end{array}$ \\
\hline $\begin{array}{l}\text { Gestão municipal de } \\
\text { resíduos e ambiente } \\
\text { institucional no Rio } \\
\text { Grande do Sul }\end{array}$ & $\begin{array}{l}\text { Explorar o problema de } \\
\text { partir das } \\
\text { correspondências entre o } \\
\text { próprio ambiente } \\
\text { institucional municipal e a } \\
\text { gestão municipal dos } \\
\text { resíduos. }\end{array}$ & $\begin{array}{l}\text { Ambiente urbano; } \\
\text { serviços urbanos; } \\
\text { sustentabilidade } \\
\text { urbana }\end{array}$ & $\begin{array}{l}\text { Análise descritiva da difusão } \\
\text { dos Planos nas microrregiões } \\
\text { do Rio Grande do Sul, o artigo } \\
\text { apresenta uma análise de } \\
\text { correspondências múltiplas que } \\
\text { proporciona de forma } \\
\text { exploratória um quadro geral da } \\
\text { gestão municipal de resíduos } \\
\text { em seu ambiente institucional. }\end{array}$ \\
\hline $\begin{array}{c}\text { Diagnóstico da } \\
\text { sustentabilidade na } \\
\text { gestão de resíduos } \\
\text { sólidos no município de } \\
\text { Marituba, região } \\
\text { Metropolitana de Belém, } \\
\text { estado do Pará }\end{array}$ & $\begin{array}{c}\text { Diagnóstico da } \\
\text { sustentabilidade da } \\
\text { gestão dos resíduos } \\
\text { sólidos no município de } \\
\text { Marituba. }\end{array}$ & $\begin{array}{l}\text { Indicadores de } \\
\text { sustentabilidade, } \\
\text { Desenvolvimento } \\
\text { sustentável, Meio } \\
\text { ambiente urbano. }\end{array}$ & $\begin{array}{l}\text { Nível de sustentabilidade de } \\
6,05, \text { que corresponde a um } \\
\text { indicador de sustentabilidade } \\
\text { médio e também a necessidade } \\
\text { de melhoria em diversos pontos } \\
\text { da gestão dos resíduos sólidos } \\
\text { no município. A aplicação da } \\
\text { matriz pode ser considerada } \\
\text { uma ferramenta útil para avaliar } \\
\text { a situação do município. }\end{array}$ \\
\hline $\begin{array}{l}\text { Diagnóstico dos danos } \\
\text { ambientais, riscos e } \\
\text { perigos presentes no lixão } \\
\text { de Massaranduba - PB }\end{array}$ & $\begin{array}{l}\text { Identificar as condições } \\
\text { de trabalho do pessoal } \\
\text { exposto diariamente aos } \\
\text { resíduos sólidos } \\
\text { envolvido na limpeza } \\
\text { urbana no lixão e em uma } \\
\text { cooperativa. }\end{array}$ & $\begin{array}{l}\text { Resíduos sólidos; } \\
\text { Lixão de } \\
\text { Massaranduba; } \\
\text { Riscos e perigos. }\end{array}$ & $\begin{array}{l}\text { Os garis e coletores não usam } \\
\text { todos os equipamentos de } \\
\text { proteção individual, sendo } \\
\text { expostos a riscos e perigos } \\
\text { eventuais do trabalho. A } \\
\text { quantificação do nível de risco } \\
\text { médio foi crítico e a magnitude } \\
\text { do perigo foi média, valores } \\
\text { preocupantes, porém possíveis } \\
\text { de serem revertidos. }\end{array}$ \\
\hline $\begin{array}{l}\text { Histórico e diagnóstico da } \\
\text { antiga área de disposição } \\
\text { de resíduos sólidos } \\
\text { urbanos da cidade de } \\
\text { Passo Fundo, Rio Grande } \\
\text { do Sul, Brasil }\end{array}$ & $\begin{array}{l}\text { Levantamento e } \\
\text { diagnóstico da situação } \\
\text { ambiental do Aterro }\end{array}$ & $\begin{array}{l}\text { Disposição } \\
\text { inadequada de } \\
\text { resíduos; } \\
\text { recuperação } \\
\text { ambienta }\end{array}$ & $\begin{array}{l}\text { No solo existente sobre os } \\
\text { resíduos sólidos urbanos } \\
\text { constataram-se alterações nas } \\
\text { concentrações dos metais } \mathrm{Zn} \text {, } \\
\mathrm{Cu}, \mathrm{Pb}, \mathrm{Cr}, \mathrm{Ni} \text { e Hg. Como a } \\
\text { principal problemática é a } \\
\text { contaminação e poluição do } \\
\text { solo e da água subterrânea, a } \\
\text { área ainda sofre as alterações } \\
\text { provenientes do descarte } \\
\text { ambientalmente incorreto de } \\
\text { resíduos, o qual já foi finalizado } \\
\text { há mais de uma década. }\end{array}$ \\
\hline $\begin{array}{l}\text { Avaliação do Perigo de } \\
\text { Contaminação do Solo } \\
\text { em Função do } \\
\text { Sistema de Disposição } \\
\text { Final de Resíduos } \\
\text { Sólidos em Valas } \\
\text { Utilizando } \\
\text { Ferramenta SIG. }\end{array}$ & $\begin{array}{c}\text { Avaliar o perigo de } \\
\text { ocorrência de } \\
\text { contaminação do solo e } \\
\text { das águas superficiais e } \\
\text { subterrâneas proveniente } \\
\text { do aterro em valas. }\end{array}$ & $\begin{array}{c}\text { Contaminação do } \\
\text { Solo por Resíduos, } \\
\text { Sistema de } \\
\text { Disposição Final de } \\
\text { Resíduos Sólidos } \\
\text { em Valas, Áreas } \\
\text { Sensíveis aos } \\
\text { Aterros em Valas. }\end{array}$ & $\begin{array}{c}\text { Em uma análise geral, dos } 17 \\
\text { municípios analisados, } 4 \text { deles } \\
\text { se encontram em uma situação } \\
\text { de alto perigo de contaminação } \\
\text { do solo. }\end{array}$ \\
\hline $\begin{array}{c}\text { Diagnóstico da } \\
\text { contaminação do solo por } \\
\text { metais tóxicos } \\
\text { provenientes de resíduos } \\
\text { sólidos urbanos e a } \\
\text { influência da matéria } \\
\text { orgânica }\end{array}$ & $\begin{array}{l}\text { Avaliar a contaminação } \\
\text { por metais pesados e sua } \\
\text { relação com a matéria } \\
\text { orgânica (MO) do solo } \\
\text { nas proximidades do Tixão_- } \\
\text { da cidade de lguatu, } \\
\text { Ceará }\end{array}$ & $\begin{array}{l}\text { Metais pesados; } \\
\text { Correlação de } \\
\text { Pearson; Adsorção; } \\
\text { Especiação }\end{array}$ & $\begin{array}{l}\text { A situação de forma geral do } \\
\text { Tixão_do município de Iguatu } \\
\text { vem comprometendo a } \\
\text { qualidade do solo da região, } \\
\text { servindo de alerta para que os } \\
\text { órgãos governamentais adotem } \\
\text { medidas de monitoramento dos } \\
\text { metais aqui estudados visando } \\
\text { assegurar a saúde humana. }\end{array}$ \\
\hline
\end{tabular}




\begin{tabular}{|c|c|c|c|}
\hline $\begin{array}{l}\text { Modelagem da } \\
\text { vulnerabilidade e do risco } \\
\text { de contaminação de } \\
\text { águas subterrâneas em } \\
\text { locais de disposição de } \\
\text { resíduos sólidos urbanos }\end{array}$ & $\begin{array}{l}\text { Relacionar o potencial } \\
\text { poluidor deum vazadouro } \\
\text { a céu aberto, situado em } \\
\text { um município brasileiro, } \\
\text { com a vulnerabilidade da } \\
\text { área a qual está inserido. }\end{array}$ & $\begin{array}{l}\text { Contaminação de } \\
\text { solos. Áreas } \\
\text { degradadas. } \\
\text { Resíduos sólidos } \\
\text { urbanos. }\end{array}$ & $\begin{array}{l}\text { Caracterização da área } \\
\text { como de baixa vulnerabilidade à } \\
\text { contaminação de águas } \\
\text { subterrâneas. O índice de } \\
\text { poluição obtido foi de } 15,1, \\
\text { demonstrando uma elevada } \\
\text { capacidade de contaminação, } \\
\text { remetendo a áreas cuja } \\
\text { intervenção imediata se mostra } \\
\text { necessária. }\end{array}$ \\
\hline $\begin{array}{l}\text { Níveis de contaminação } \\
\text { por metais pesados na } \\
\text { área de disposição de } \\
\text { resíduos sólidos no } \\
\text { município de Januária-MG }\end{array}$ & $\begin{array}{c}\text { Avaliar os níveis de } \\
\text { contaminação por metais } \\
\text { pesados no solo do } \\
\text { vazadouro a céu aberto } \\
\text { do município de Januária } \\
\text { - MG. }\end{array}$ & $\begin{array}{l}\text { Contaminação do } \\
\text { solo. Tóxico. } \\
\text { Vazadouro a céu } \\
\text { aberto. }\end{array}$ & $\begin{array}{c}\text { Dentre os elementos } \\
\text { analisados apenas o Zinco (Zn) } \\
\text { ultrapassou o valor orientador } \\
\text { de Referência de Qualidade } \\
\text { (VRQ), mesmo não sendo } \\
\text { detectado níveis alarmantes de } \\
\text { contaminação do solo, torna-se } \\
\text { interessante a desativação do } \\
\text { vazadouro visto que o mesmo } \\
\text { se encontra em desacordo com } \\
\text { a Lei } 12.305 / 2010 \text {. }\end{array}$ \\
\hline
\end{tabular}

De acordo com Marchi (2015) lixões consistem em locais de disposição de lixo sem algum controle técnico, prejudiciais à saúde humana e ao meio ambiente. Pimenta et al. (2020) corroboram com a afirmação, visto que o chorume, líquido escuro, resultado da decomposição e putrefação de matéria orgânica, são contaminantes que percolam pelos compartimentos do solo. Assim, a identificação de tais impactos é fundamental, visto que a caracterização e avaliação dos mesmos possibilita a substituição da suposição dos malefícios dos vazadouros pelas consequências reais vistas nos locais.

Quanto às palavras-chave, nota-se a assídua repetição do termo "contaminação", percebendo-se a preocupação dos autores em relação a disposição inadequada de resíduos sólidos, além da apresentação da contaminação do solo, água e meio ambiente de forma geral, gerando consequentes problemas de saúde para a população do entorno.

A leitura dos resultados apresentou uma realidade de contaminação do solo, dos recursos hídricos, do ar e interferência direta na saúde da comunidade que reside próximo aos locais investigados. Os trabalhos apresentaram a queima dos resíduos sólidos urbanos como fonte de emissão de fumaça e cinzas, ocasionando fontes de poluição do ar, gerando incômodo e problemas de saúde para a população que reside próximo ao local. Percebeu-se também a incidência dos metais pesados que podem alterar a qualidade do ar, apesar da crença de que a distribuição dos metais pesados ocorra por meio da contaminação da água ou de alimentos ingeridos, estes são em sua maior parte carreados de um local para outro por via aérea.

Outros estudos similares que também denunciam impactos resultantes da disposição inadequada dos resíduos sólidos urbanos, corroboram com os resultados apresentados. Silva et al. (2020), investigaram os impactos gerados por um lixão na cidade de Santa Helena de Goiás, comprovando também a existência de resíduos industriais, da construção civil e resíduos hospitalares, constatando a poluição do solo, da água e do ar e presença de vetores transmissores de doenças. Assim como Oliveira et al. (2016) que também afirmaram que as áreas utilizadas como destinação final de resíduos sólidos urbanos, geralmente representadas pelos lixões, apresentam alto potencial de poluição, interferindo de forma negativa, na qualidade de vida e na saúde humana e ambiental do seu entorno.

Dessa forma, percebe-se a preocupação das pesquisas para identificação dos impactos ambientais causados pela disposição inadequada de resíduos sólidos, 
além da apresentação da contaminação do solo, água e meio ambiente de forma geral, gerando consequentes problemas de saúde, visto que a pesquisa da ABRELPE (2018), informou que de 72,7 milhões de toneladas de resíduos sólidos coletadas no Brasil em 2018, 59,5\% tiveram disposição final adequada e foram encaminhadas para aterros sanitários, isso revela que houve expansão de $2,4 \% \mathrm{em}$ relação ao valor total do ano anterior, porém, ainda comparando as disposições entre as regiões, destaca-se a região Sul do País com a menor quantidade de municípios que destinam os resíduos no lixão (42), em contrapartida, a região Nordeste apresenta o maior número de municípios com destinação ao lixão (844).

\section{Determinação das consequências dos destinos inadequados dos resíduos sólidos urbanos}

A determinação das consequências dos destinos inadequados dos resíduos sólidos urbanos é expressa através do Quadro 5 fundamentada na frequência da citação de cada consequência apontada nos trabalhos investigados, o que revelou os danos ambientais como a consequência mais citada, visto que $90,90 \%$ das pesquisas apresentaram danos ambientais decorrentes da destinação dos resíduos sólidos urbanos, seguido da contaminação do solo, cerca de $72,72 \%$ de citações, logo após tem-se as citações que apresentaram os danos à saúde humana, $63,63 \%$ e contaminação da água, 54,54\%.

QUADRO 5. Consequências mais citadas nos trabalhos lidos

\begin{tabular}{l|c}
\hline Consequências & Frequência de citações \\
\hline Danos ambientais & $90,9 \%$ \\
\hline Contaminação do solo & $72,72 \%$ \\
\hline Danos à saúde humana & $63,63 \%$ \\
\hline Contaminação da água & $54,5 \%$ \\
\hline
\end{tabular}

Os resultados obtidos corroboram com pesquisas realizadas na área de lixão do município de Assú-RN sob a direção de Andrade e Alcântara (2016). Os autores apontaram os danos ambientais a partir das perceptíveis mudanças na fauna e na flora do local estudado, visto que a partir da inexistência vegetal local, houve o desaparecimento tanto de espécies de vegetais quanto de animais endêmicos, em compensação, notou-se o crescimento do número de garças, urubus e porcos, condição que acarretou desequilíbrio na área. Em relação a contaminação do solo, os autores apontaram modificações das características físico-químicas e biológicas do solo, degradando a fertilidade. Além disso, os autores identificaram a coloração escura do solo, e a produção desordenada de chorume.

Ainda de acordo com Andrade e Alcântara (2016) o ar da localidade apresentava alterações decorrentes da queima clandestina dos resíduos, com o lançamento da fumaça negra e fuligem, o ar tornava-se irrespirável, danificando a saúde das pessoas que residiam no local, sendo que também foram percebidos corpos aquáticos próximos ao lixão, certamente contaminados pelo chorume. Silva et al. (2020) além de retratar os riscos de contaminação descritos anteriormente, destacam os perigos para os seres humanos, especialmente, quando consideram a composição da parte orgânica que apresenta circunstâncias favoráveis para hospedar organismos, dentre os quais encontram-se os patógenos, como helmintos, na forma de ovo e larva, e vírus. 


\section{CONCLUSÃO}

A redução da geração excessiva e destinação final adequada dos resíduos sólidos urbanos (RSU) apresentam-se como um dos maiores desafios que a sociedade moderna enfrenta, visto que tal questão tornou-se uma preocupação mundial em decorrência dos impactos socioambientais nocivos em decorrência da disposição inadequada dos resíduos sólidos urbanos.

$\mathrm{Na}$ Revisão Sistemática da Literatura - RSL Foram identificados 3.201 trabalhos, dentre estes, foram selecionados 14 para a revisão sistemática. A leitura dos materiais possibilitou o conhecimento de que resíduos sólidos, além da apresentação da contaminação do solo, água e meio ambiente de forma geral, gerando consequentes problemas de saúde para a população do entorno.

Entre os anos de 2012 a 2020, destacaram-se em número de publicações os anos de 2018 e 2019, o que revela com o passar dos anos, o crescimento populacional e do consumismo, que implica na maior geração de produtos, e consequentemente, resíduos sólidos. Entre os estados que mais publicaram, os que obtiveram maior notoriedade foram Minas Gerais e Rio Grande do Sul o que resulta da preocupação com o aumento da coleta de resíduos sólidos na região Sudeste que passou de 103.741 toneladas/dia em 2017 para 105.977 toneladas. dia $^{-1}$ em 2018 e a região Sul passou de 21.327 toneladas/dia coletados em 2017 para 21.561 toneladas/ dia coletados em 2018. Entre as áreas do ensino, destacou-se pelo número de publicações, a área de engenharias e meio ambiente.

A realidade de contaminação do solo, dos recursos hídricos, do ar e interferência direta na saúde da comunidade que reside próximo aos locais investigados são os resultados mais vistos diante da leitura dos trabalhos, além da constatação da queima dos resíduos sólidos urbanos em alguns lixões, ocasionando poluição do ar e gerando incômodo e problemas de saúde para a população que reside próximo ao local. É também significativo o número de pesquisas que apresentam a incidência dos metais pesados que podem alterar a qualidade do ar, apesar da crença de que a distribuição dos metais pesados ocorra por meio da contaminação da água ou de alimentos ingeridos.

Acerca dos impactos ambientais oriundos da destinação inadequada dos resíduos sólidos urbanos percebeu-se que o solo, água, flora e fauna foram os fatores ambientais mais degradados pelas atividades nas áreas em estudo. $O$ material analisado apresentou os danos ambientais como a consequência mais citada, visto que $90,9 \%$ das pesquisas apresentam danos ambientais decorrentes da destinação dos resíduos sólidos urbanos, seguido da contaminação do solo, cerca de $72,7 \%$ de citações, logo após os danos à saúde humana com $63,6 \%$ e; finalmente com a contaminação da água com $54,5 \%$.

Neste viés o desafio das cidades está pautado na aplicação da gestão de resíduos sólidos tendo como principal finalidade a eliminação dos riscos à saúde e ao ambiente, deve-se defender a necessidade novas técnicas de tratamento dos resíduos sólidos urbanos tais como compostagem, coleta seletiva e a incineração, além da implantação de programas educacionais.

Dessa forma, é preciso propor mais pesquisas sobre os impactos de resíduos sólidos urbanos nas cidades para que a população compreenda os danos causados pela falta de gerenciamento dos resíduos sólidos. A informação e educação ambiental podem promover uma sensibilização e cobrança da aplicação da Política Nacional de Resíduos sólidos, a percepção ambiental apresenta-se como importante ferramenta interdisciplinar para modificação do atual estado dos resíduos no Brasil. 


\section{REFERÊNCIAS}

ABRELPE. Panorama dos resídos sólidos no Brasil, Associação Brasileira das Empresas de Limpeza Pública e Resíduos Especiais. URL: https://abrelpe.org.br/.

ANDRADE, A. T. S.; ALCÂNTARA, R. L. Resíduos Sólidos Urbanos e Impactos Socioambientais no Bairro "Lagoa do Ferreiro", Assu/RN. Revista Eletrônica em Gestão, Educação e Tecnologia Ambiental Santa Maria, v. 20, n. 1, jan.-abr. 2016, p. 16-31. DOI: https://doi.org/10.5902/2236117020029.

ANDRADE, C. S.; AMARO, C. M.; OLIVEIRA, L. A. C. Análise do gerenciamento de resíduos sólidos urbanos na cidade de Itabira: Uma ênfase na coleta seletiva (MG). Dissertação em Engenharia Ambiental - Programa de Pós-Graduação em Engenharia Ambiental. Núcleo de Pesquisas e Pós-Graduação em Recursos Hídricos, Universidade Federal de Ouro Preto, Ouro Preto, 2018. URL: http://www.repositorio.ufop.br/jspui/handle/123456789/10592.

AZEVEDO, P. B. DE; LEITE, J. C. A.; OLIVEIRA, W. S. N. DE; SILVA, F. M.; FERREIRA, P. M. L. Diagnóstico da degradação ambiental na área do lixão de Pombal - PB. Revista Verde de Agroecologia e Desenvolvimento Sustentável, v. 10, n. 1, p. 20 - 34, 24 Feb. 2015. DOI: https://doi.org/10.18378/rvads.v10i1.3294.

BARBOSA, T. R. C. G. B.; CEZAR, L. C.; REIS, M. C. T.; JÚNIOR, F. F. Panorama acadêmico sobre resíduos sólidos: análise da produção cientifica a partir do marco legal do setor. Revista Metropolitana de Sustentabilidade. Vol. 5, n. 2, 2015.

BRAGA, J.; BENEDITO, P. F.;HESPANHOL, I.; LOTUFO, C.; GILERTO; et al. Introdução à engenharia ambiental. São Paulo: Prentice Hall, 2012.

BRASIL. Lei no 12.305 de 02 de agosto de 2010. Institui a Politica Nacional de Resíduos Sólidos; altera a lei n.9.605, de 12 de fevereiro de 1998; e dá outras providencias. Diário Oficial da República Federativa do Brasil, Poder Executivo, Brasília DF.

BRASIL, Conselho Nacional do Meio Ambiente. Resolução n.001, de 23 de janeiro de 1986. Dispõe sobre critérios básicos e diretrizes gerais para o Relatório de Impacto Ambiental - RIMA. Diário Oficial da República Federativa do Brasil, Brasília, DF, 17 fev. 1986.

CARBONAI, D.; BAUM, J.; CAMIZ, S. Gestão municipal de resíduos e ambiente institucional no Rio Grande do Sul. EURE (Santiago) ,v.46, no 138, Santiago, 2020. DOI: http://dx.doi.org/10.4067/S0250-71612020000200139.

CEZAR, L. C.; BARBOSA, T. R. C. G.; REIS, M. C. T.; JÚNIOR, F. F. Panorama acadêmico sobre resíduos sólidos: análise da produção cientifica a partir do marco legal do setor. Revista Metropolitana de Sustentabilidade - RMS, São Paulo, v. 5, n. 2, p. 14-33, maio/ago., 2015.

DEUS, R. M.; BATTISTELLE, R. A. G.; SILVA, G. H. R. Resíduos sólidos no Brasil: contexto, lacunas e tendências. Revista Eng Sanitária e Ambiental, v.20, no 4, out/dez 2015.

DOI: https://www.scielo.br/j/esa/a/jLnBfyWrW7MPPVZSz46B8JG/?format=pdf\&lang=pt. 
FERREIRA, M. C.; LOPES, J. F. O Crescimento Populacional e os Impactos Ambientais. Revista Científica Multidisciplinar Núcleo do Conhecimento. Ed. 06, Vol. $\quad 02, \quad$ pp. 188-195, 2020. ISSN: 2448-0959. DOI: https://www.nucleodoconhecimento.com.br/meio-ambiente/crescimentopopulacional.

FOGLIATTI, M. C.; FILIPPO,S; GOUDARB, B. Avaliação de Impactos ambientais aos sistemas de transporte. Rio de Janeiro: interciência, 2014.

FRACASSO, M.; DALEPIANE, R. M.; PORSCH, M. R. M. H.; PFULLER, E. E.; SILVA, R.S. Diagnóstico E Proagnóstico Dos Rsu Para Município De Sananduva/RS. Revista Holos, v. 04, 2017. DOI: https://doi.org/10.15628/holos.2017.3699

FRATA, K. D. S. A.; TONELI, J. T. C. L.; AMARANA, K. B. B.; ANTONIO, G. C. Revisão sistemática da situação da gestão de resíduos sólidos urbanos no brasil, visando o seu aproveitamento energético. In: Congresso Brasileiro de Gestão Ambiental, no 10, 2019, Fortaleza-CE,.

FREIRE, V. A. F.; SILVA, A. M.; SILVA, D. S.; FREIRE, E. A. Diagnóstico dos danos ambientais, riscos e perigos presentes no lixão de Massaranduba - PB. Research, Society and Development, v. 9, n. 3, 2020. DOI: http://dx.doi.org/10.33448/rsdv9i3.2442

GIL, A. C. Como elaborar projetos de pesquisa. 6 Ed. - São Paulo: Atlas, 2017.

GOLVEIA, N. Resíduos sólidos urbanos: impactos socioambientais e perspectiva de manejo sustentável com inclusão social. Ciência e Saúde Coletiva, v. 17, n.6. DOI: https://doi.org/10.1590/S1413-81232012000600014

LAKATOS, E. M.; MARCONI, M. A. Metodologia do trabalho científico: projetos de pesquisa, pesquisa bibliográfica, teses de doutorado, dissertações de mestrado, trabalhos de conclusão de curso. 8. ed. - São Paulo: Atlas, 2017.

LEITE, N. M. G.; PINHEIRO, A. R. S.; MADEIRA, C. S. R.; BRITO, R. M.; SOUZA, M. $\mathrm{O}$. J.; et al. A influência da disposição final dos resíduos sólidos nos recursos hídricos: uma revisão sistemática / The influence of the final disposal of solid waste on water resources: a systematic review. Brazilian Journal of Development, v. 7, $\mathrm{n}$. 2, 2021. DOI: $\mathrm{rg} / 10.34117 / \mathrm{bjdv} 7 \mathrm{n} 2-084$

MAIELLO, A.; BRITTO, A. L. N. P.; VALLE, T. F. Implementação Da Política Nacional De Resíduos Sólidos. Revista de administração pública, Rio de Janeiro, v. 52, n. 1, p. 24-51, jan./fev. 2018. DOI: https://doi.org/10.1590/0034-7612155117

MARCHI, C. M. D. F. Novas perspectivas na gestão do saneamento: apresentação de um modelo de destinação final de resíduos sólidos urbanos. Revista Brasileira de Gestão Urbana. Salvador-BA, v. 7, n. 1, p. 91-105, jan-abr. 2015. DOI: https://doi.org/10.1590/2175-3369.007.001.AO06

MARQUES, R. F. P. V.; SILVA, A. M.; RODRIGUES, L. S; COELHO, G. Impactos da disposição de resíduos sólidos urbanos na qualidade da água de superfície em três 
cidades de Minas Gerais - Brasil. Agricultural Engineering, Ciência agrotec. v. 36, n. 6, 2012. DOI: https://doi.org/10.1590/S1413-70542012000600010

MELO, E. F. R. Q.; ANDRADE, L. C.; MAGRO, F. G. Histórico e diagnóstico da antiga área de disposição de resíduos sólidos urbanos da cidade de Passo Fundo, Rio Grande do Sul, Brasil. Revista Ambiência, v. 12, n. 4, 2016. DOI: https://revistas.unicentro.br/index.php/ambiencia/article/view/2661

MILHOME, M. A. L.; HOLANDA, J. W. B.; ARAUJO, N. J. R.; NASCIMENTO, R. F. Diagnóstico da Contaminação do Solo por Metais Tóxicos Provenientes de Resíduos Sólidos Urbanos e a Influência da Matéria Orgânica. Revista Virtual de Química. v. 10, n. 1, 2018. DOI: http://static.sites.sbq.org.br/rvq.sbq.org.br/pdf/v10n1a07.pdf

NOVAIS, T. M. F.; CRUZ, M. C. C.; AZEVEDO, M. A. Modelagem da vulnerabilidade e do risco de contaminação de águas subterrâneas em locais de disposição de resíduos sólidos urbanos. Revista Águas Subterrâneas. v. 33, n. 3, 2019. DOI: https://doi.org/10.14295/ras.v33i3.29526

OliveIRA, J. A. M.; MEDEIROS, P. C.; OliveIRA, C. M. M.; SANTOS, A. F. S. Níveis De Contaminação Por Metais Pesados Na Área De Disposição De Resíduos Sólidos No Município De Januária-MG. Revista Gestão e Sustentabilidade. $\begin{array}{llllll}\text { Florianópolis, } & \text { v. } & 8, & \text { n. } & 1, & \text { p.629-640, }\end{array}$ DOI:http://www.portaldeperiodicos.unisul.br/index.php/gestao_ambiental/article/view/ 6032/4341

OLIVEIRA, B. O. S.; TUCCI, C. A. F.; SANTOS, A. A.; JÚNIOR, A. F. N. Avaliação dos solos nas águas de influencia de disposição de resíduos sólidos urbanos de Humaitá, Amazonas. Revista Brasileira de Engenharia Sanitária Ambiental. v 21, n. 3 , $2016 . \quad$ DOI: https://www.scielo.br/j/esa/a/XLdpSSxpXLFyZmBVHnz3F4S/?lang=pt

PIMENTA, S. S.; COSTA, D. S.; SILVA, E. R. A. C.; AROUCHE-LIMA, I. M. Análise da gestão gerenciamento de resíduos urbanos em Alcântara (Maranhão-Brasil). Revista Meio Ambiente (Brasil),v. 2, n. 1, p. 25-33, 2020.

PINHEIRO, N. C. A.; MOCHEL, F. R. Diagnóstico de áreas contaminadas pela disposição final de resíduos sólidos no município de Paço do Lumiar (MA). Revista Engenharia Sanitária e Ambiental, v. 23 n. 6, 2018. DOI: https://doi.org/10.1590/s1413-41522018173619

RODRIGUES, G. S. M.; PEIXOTO, A. S. P. Avaliação do Perigo de Contaminação do Solo em Função do Sistema de Disposição Final de Resíduos Sólidos em Valas Utilizando Ferramenta SIG. IN: XIX Congresso Brasileiro de Mecânica dos Solos e Engenharia Geotécnica. Geotecnia e Desenvolvimento Urbano COBRAMSEG, 2018, Salvador, Bahia, Brasil.

SILVA, G.; LOPES, A. A., SILVA JúNIOR, E. D.; SALES, A. S. B. Avaliação da área de disposição final de resíduos sólidos de um município de pequeno porte mediante os critérios técnicos e ambientais. Revista Nacional de gerenciamento de cidades. v.8, n. 61, 2020. 
SILVA, M. M. P. Manual Teórico Metodológico de Educação ambiental. ISBN 978 8562198. Campina Grande-PB: Maxgraf Ltda. 2016. 174 p.

SILVA, V. G. L.; ARAÚJO, R.; BARBOSA, G. F.; GOMES, R. B.; SILVA, M. M. P.; et al. Formação em educação ambiental para líderes comunitários que atuam em GurjãoPB: uma contribuição à política municipal de resíduos sólidos. In: Congestas Congresso Brasileiro de Gestão Ambiental e Sustentabilidade, João Pessoa. Anais. João Pessoa, 2015.

SOUZA, C. C. F.; MELO, B. R.; SANTOS, M. A. S.; RABELLO, F. K.; MARTINS, C, $\mathrm{M}$; ; et al.. Diagnóstico Da Sustentabilidade $\mathrm{Na}$ Gestão De Resíduos Sólidos No Município De Marituba, Região Metropolitana De Belém, Estado Do Pará. Revista Metropolitana de Sustentabilidade.v. 9 n. 2, 2019.

VASCONCELOS, M. C. Aplicação da técnica análise envoltória de dados na gestão de resíduos sólidos urbanos (RSU): uma revisão sistemática da produção acadêmica internacional. In: Congresso Nacional de Administração, 2018, Sucre- Bolívia.

YIN, R. K.; O Estudo de Caso. Porto Alegre: Bookman, 2005. 